\title{
Infrainguinal open reconstruction: a review of surgical considerations and expected outcomes
}

\author{
This article was published in the following Dove Press journal: \\ Vascular Health and Risk Management \\ 8 May 2017 \\ Number of times this article has been viewed
}

\section{Sevan R Komshian \\ Kimberly Lu \\ Steven L Pike \\ Jeffrey J Siracuse}

Division of Vascular and Endovascular Surgery, School of Medicine, Boston University Boston, MA, USA
Correspondence: Jeffrey J Siracuse Boston Medical Center, School of Medicine, Boston University, 88 East Newton Street, Collamore 5, Boston, MA 02210, USA

Email jeffrey.siracuse@bmc.org

\begin{abstract}
Infrainguinal arterial occlusive disease can lead to potentially disabling and limbthreatening conditions. Revascularization may be indicated for claudication, rest pain, or tissue loss. Although endovascular interventions are becoming more prevalent, open surgeries such as endarterectomy and bypass are still needed and performed regularly. Open reconstruction has been associated with postoperative morbidity, both at the local and at the systemic levels. Local complications include surgical site infections (SSIs 0-5.3\%), graft failure (12-60\%), and amputation (5.7-27\%), and more systemic issues include cardiac (2.6-18.4\%), respiratory (2.5\%), renal (4\%), neurovascular (1.5\%), and thromboembolic ( $0.2-1 \%)$ complications. While such outcomes present an additional challenge to the postoperative management of surgical patients, it may be possible to minimize their occurrence through careful risk stratification and preoperative assessment. Therefore, individualized selection of candidates for open repair requires weighing the need for intervention against the likelihood of adverse outcomes based on preoperative risk factors. This review provides an overview of open reconstruction, focusing on identifying the clinical indications for surgery and perioperative morbidity and mortality.
\end{abstract}

Keywords: infrainguinal bypass, outcomes, risk factors

\section{Introduction}

Peripheral arterial disease (PAD) is one of the leading causes of atherosclerotic morbidity in the US, affecting 8-10 million people. ${ }^{1}$ As this number rises due to the persistence of cigarette smoking and the aging population, revascularization continues to play an increasingly important role in PAD management when medical therapy is insufficient or when there is critical limb ischemia (CLI). ${ }^{2,3}$ Although endovascular intervention is becoming more common and is in many cases the first-line treatment, there is still a role for open surgical intervention. ${ }^{4}$ Anatomic considerations as well as overall patient health and influence of comorbidities provide an integral role in guiding treatment ${ }^{5,6}$

Deciding on the optimal strategy for revascularization for infrainguinal PAD in symptomatic patients begins with a choice between endovascular and open approaches. While endovascular therapy is less invasive and has fewer perioperative risks, it is generally thought to produce diminished patency when compared with open procedures such as endarterectomy and bypass., ${ }^{4-9}$ Without a definitive indication for one approach over the other, the choice depends on a consideration of patient- and disease-specific factors that stratify risk among operative techniques. In patients with major tissue loss, a good-quality venous conduit, and an anatomic pattern consistent with multilevel disease, defined as Trans-Atlantic Inter-Society Consensus Document on the Management of Peripheral Arterial Disease (TASC) C or D, open intervention 
is often advocated but still remains an issue of contention. ${ }^{10}$ Nevertheless, patients chosen to undergo open operations experience perioperative mortality in excess of $2 \%$ and complication rates remain $>20 \%$ in some cohorts. ${ }^{11,12}$ This review aims to explore the current practice of infrainguinal reconstruction by providing an overview of open procedures and their associated outcomes.

\section{Clinical indications for open revascularization}

The decision to perform open repair of occlusive disease often begins with a consideration of the clinical manifestations of PAD. Symptomatic PAD presents as intermittent claudication, rest pain, or tissue loss. Intermittent claudication classically manifests as reproducible lower extremity aching or fatigue on exertion that is relieved with rest. Vascular origin of these symptoms, as opposed to musculoskeletal or neuropathic etiologies, is confirmed by an ankle brachial index $<0.9$, although this may be falsely elevated if there are calcified vessels. ${ }^{13}$ Several studies have shown that outside of certain populations, claudication is unlikely to progress to more severe disease involving rest pain in the short term. ${ }^{14-16}$ Therefore, patient education, exercise therapy, and medical treatment are offered initially, while surgical repair is reserved for individuals who fail conservative and medical therapy or for patients with severe disability. ${ }^{6}$

Surgical management of patients with PAD is the preferred method of treatment upon the development of CLI, which manifests as rest pain and, in more severe cases, tissue loss and gangrene. Although CLI presents in only $1-3 \%$ of PAD patients, its causation of restricted lower extremity tissue perfusion has a broad impact on local and global physiologic processes. This necessitates revascularization to avoid unremitting pain, limb amputation, debilitating infection, and death. ${ }^{17-19}$ The Bypass versus Angioplasty in Severe Ischemia of the Leg (BASIL) trial has compared the outcomes of the two methods of revascularization. ${ }^{20-22}$ Despite similar perioperative mortality and higher perioperative morbidity in the surgery group, data indicate improved outcome in open surgical intervention in patients expected to survive more than 2 years due to higher amputation-free survival and lower all-cause mortality when compared with endovascular methods. The BASIL trial was limited by a lack of advanced endovascular treatment and hemodynamic monitoring. The Best Endovascular versus Best Surgical Therapy in patients with Critical Limb Ischemia (BESTCLI) trial, which is currently enrolling, seeks to clarify which patients will benefit from open versus endovascular options. $^{23}$ Open surgical options include endarterectomy, often the treatment of choice for the common femoral artery (CFA) and bypass.

\section{Common femoral endarterectomy (CFE)}

Endarterectomy is the most common modality to revascularize the CFA and the profunda femoris artery in the treatment of PAD. Although CFE was previously the gold standard for artherosclerotic lesions of the CFA, there has recently been a shift toward endovascular therapy for revascularization of the CFA. ${ }^{4,7}$ Endovascular therapy has shown decreased patency but similar perioperative morbidity and mortality for common femoral disease. ${ }^{8,9,24}$ However, endovascular therapies may compromise blood flow to the profunda femoris, which originates at the femoral bifurcation. Endovascular stents at the CFA are also susceptible to fracture and kinking due to frequent flexion and movement at the inguinal ligament. ${ }^{25,26}$ Stenting in the CFA has been associated with high risk of intervention in a recent study, although there remains a lack of consensus with conflicting published data. ${ }^{24,27,28}$ The American College of Surgeons' National Surgical Quality Improvement Project database demonstrated that CFE is well tolerated by patients with PAD, showing a 30 -day mortality rate of $1.5 \%$ and at least one complication in $7.9 \%$ of patients. The most common complications were superficial surgical site infection (SSI; $6.3 \%$ ), urinary tract infection $(1.7 \%)$, and deep vein thrombosis (DVT; $0.5 \%$ ). ${ }^{29}$ These rates were comparable to those seen in endovascular intervention, revealing similar perioperative outcomes but favorable long-term postoperative outcomes in patients undergoing CFE. When comparing CFE to hybrid procedures involving endovascular repair, no difference in patency was observed between the two groups. ${ }^{30}$ At 1 year postoperatively, freedom from intervention in the ipsilateral limb is reported as $82 \%$ and survival rate as $89 \%$ for $\mathrm{CFE}$.

\section{Bypass and expected outcomes}

Surgical bypass uses autologous or prosthetic vein grafts to reroute blood flow to poorly perfused distal sites, circumventing vessel occlusions. The efficacy of reconstruction is heavily influenced by the anatomic location of the occlusion, as different arteries face varying hemodynamic stresses dependent on vessel size. Definitions of patency and stenosis can vary depending on the study and the type of intervention (bypass or endovascular). This makes direct comparison of retrospective studies challenging. 


\section{Femoral-popliteal disease}

Bypass of the femoral and popliteal arteries has generally proven to be durable and successful in suitable patient populations. Maximal hemodynamic supply and minimal risks for infection are achieved by the use of a greater saphenous vein (GSV) graft, producing 5-year patency at $70 \% .{ }^{31}$ However, studies have found that $\sim 40 \%$ of patients do not have an ipsilateral vein of sufficient length to use for the procedure. ${ }^{32,33}$ In the absence of a history for PAD in the other limb, contralateral saphenous vein may be used instead. Arm vein, either single segment or composite, is also an option for conduit if there is not any GSV or if the contralateral leg has PAD and good vein. ${ }^{34}$ Prosthetic grafts are used in the absence of suitable autologous vessels, although they exhibit mildly lower long-term durability, especially with distal vessel location. ${ }^{35,36}$ Despite high overall patency, femoral-popliteal bypass surgery is associated with a number of complications including lower extremity lymphedema, wound infection, graft occlusion, respiratory failure, acute kidney injury (AKI), stroke, and cardiovascular accident, contributing to a 30-day morbidity rate of $37 \% .{ }^{37,38}$ Identification and prevention of patient risk factors is essential to minimize such high rates of these perioperative complications.

\section{Tibial disease}

With high amputation and 1-year mortality rates, patients with infrapopliteal occlusive disease represent a particularly challenging cohort to manage. ${ }^{1,39}$ Much of this stems from the anatomically distal site of occlusion and necessitates a longer venous conduit when compared with femoral-popliteal disease. The use of autologous veins are preferred and have been shown to produce similar long-term outcomes compared to the more proximal surgeries with 5-year patency rates at $47 \% .{ }^{6,40}$ Meanwhile, the use of spliced or prosthetic grafts has been linked to diminished durability and higher rates of complications, and they may not be ideal for distal reconstruction. ${ }^{41}$ Furthermore, tibial disease is often associated with diabetes, which may compromise revascularization efforts and negatively impact graft patency ${ }^{42}$ Careful selection of patients, use of appropriate operative techniques, and vigilant postoperative management are especially important to ensure clinical success in this cohort. ${ }^{43}$

\section{Conduit}

The type of conduit used for bypass can heavily influence surgical outcome and should be selected on a patient to patient basis. The GSV is an ideal conduit due to its ease of harvest, vessel length, and inconsequential removal. ${ }^{38}$ Primary patency rates at 1,5 , and 10 years are $85 \%, 72 \%$, and $55 \%$, respectively. ${ }^{44}$ In infrainguinal disease, such durability has proven to be higher than with other conduits. Furthermore, GSV grafts have been associated with superior amputationfree survival in comparison to prosthetic grafts. ${ }^{9,20}$

In the absence of suitable GSV, other autologous veins such as superficial arm veins may be considered. Although the cephalic and basilic veins may be used as a single segment, they are often combined into a composite conduit to provide sufficient length in the setting of infrainguinal surgery. Single-segment cephalic vein has been shown to have the best durability of the three options..$^{45}$ One long-term study revealed 5-year patency and limb salvage rates of 55\% and $72 \%$, respectively. ${ }^{34}$ These rates are still above those for comparable prosthetic conduits. ${ }^{46}$

Prosthetic grafts are used when autologous conduits are not available or suitable. Of these, expanded polytetrafluoroethylene (ePTFE), polyethylene terephthalate (Dacron), and heparin-bonded ePTFE grafts are most common. Generally, their use in infrainguinal bypass has been shown to have inferior results compared to autologous GSV. Four-year patency rates for infrainguinal bypass with ePTFE and GSV are 54\% and $76 \%$, respectively ${ }^{47}$ Prosthetic grafts to tibial vessels have particularly poor outcomes, with 36-month primary patency rates at $20 \%$ and limb salvage rates of $55 \%{ }^{41}$ Meanwhile, heparin-bonded grafts have demonstrated improved longterm outcomes and show promise as a prosthetic option..$^{48,49}$

\section{Surgical site complications}

While patency is the primary measure of long-term success for bypass revascularization, it can be affected by a number of perioperative complications at the site of surgical repair that compromise technical success and quality of life (Table 1). Although there are a number of local complications, SSI, graft occlusion, and limb loss will be reviewed here. Each complication discussed is associated with risk factors that should be considered prior to surgery to avoid poor outcomes (Table 2).

SSIs occur frequently in infrainguinal bypass in the 30-day perioperative window, presenting in as many as $11 \%$ of cases regardless of bypass origin..$^{50}$ The common pathogens involved include Staphylococcus epidermidis (37\%), methicillinsensitive Staphylococcus aureus (26\%), and Enterococcus $(10 \%) .{ }^{51}$ SSI often presents as graft infection. Reported rates of graft infection after bypass involving the femoral artery are $3.8 \%$. Independent risk factors, such as female sex, diabetes mellitus, active infection at the time of bypass, and redo bypass, are shown to be associated with graft infection. In patients with prosthetic grafts, the rates of graft infection 
Table I Postoperative complications

\begin{tabular}{ll}
\hline Complications & \\
\hline Surgical site & \\
Infection* & $0-5.3 \%^{37}$ \\
Graft failure** & $12-60 \%^{80}$ \\
Amputation** & $5.7-27 \%^{81}$ \\
Systemic & \\
Cardiovascular* & $2.6-18.4 \%^{66}$ \\
Respiratory failure* & $2.5 \%^{69}$ \\
Renal failure* & $4 \%^{71}$ \\
Cerebrovascular* & $1.5 \%^{11}$ \\
Venous thromboembolism* & $0.2-1 \%^{76}$ \\
Death* & $0-6.3 \%^{82}$ \\
\hline
\end{tabular}

Notes: *30-Day postoperative range. **I-Year postoperative range.

associated with the above risk factors are $6.8 \%, 6.5 \%, 11.7 \%$, and $11.5 \%$, respectively. As prosthetic grafts are susceptible to infection, autologous conduits for infrainguinal bypass or endovascular revascularization are recommended in highrisk patients. ${ }^{51}$ Although graft infections may not increase postoperative mortality, they often contribute to lower limb amputation and may require removal or attempts at rescue with vacuum-assisted devices and rotational muscle flaps. ${ }^{52-55}$

Bypass vessels are often monitored for occlusion at regular intervals postoperatively. ${ }^{56}$ Over time, venous conduits are prone to undergo neointimal hyperplasia and ultimately vessel restenosis caused by hemodynamic stresses of the physiological environment. ${ }^{57}$ This is particularly true for prosthetic grafts, as discussed previously. Other factors predisposing to neointimal thickening include patient hypertension, diabetes, and hyperlipidemia ${ }^{58}$ Meanwhile, infrainguinal bypass patients are susceptible to developing graft occlusions due to enhanced local hypercoagulability in the perioperative setting, with rates reaching up to $4.5 \% .{ }^{59}$ Various patient- and surgery-specific predictors for perioperative graft hypercoagulability include age, preoperative ambulatory status, advanced PAD, long duration of surgery, and intraoperative local trauma. Technical errors such as small vein diameter, inappropriate conduit selection, and graft length $>50 \mathrm{~cm}$ are also associated with early graft failure. ${ }^{33}$

Impending graft failure can be identified using clinical symptoms, segmental blood pressures, and particularly duplex ultrasound ${ }^{60}$ When performed early postoperatively and assessed alongside aforementioned risk factors for graft occlusion, duplex ultrasound may be useful in identifying grafts at high risk of failure. ${ }^{61}$ Occlusion may necessitate graft revision, which can be accomplished through either endovascular methods or a second open intervention. Open reintervention has been shown to be more durable than endovascular repair in thrombosed grafts undergoing salvage, with 12 -month amputation rates of $75 \%$ and $56 \%$, respectively $(p=0.006) .{ }^{62}$ Furthermore, endovascular-revised grafts require higher rates of reintervention to maintain patency, although they are less invasive. ${ }^{8}$

After lower extremity bypass, due to graft failure, persistent infection, or necrosis, amputation may still be necessary. Overall, 1-year postoperative freedom from major amputation and amputation-free survival has been reported as $87 \%$ and $76 \%$, respectively. ${ }^{63}$ Despite patent bypass grafts, some patients do not achieve limb salvage, and studies have demonstrated similar 1-year amputation rates in patients with patent (6.3\%) and occluded (5.7\%) grafts. ${ }^{64}$ Thus, identification of patient comorbidities contributing to amputation in patent grafts in addition to prevention of graft failure is essential in limiting limb loss. Patients with diabetes, end-stage renal disease, previous amputations, peripheral neuropathy, preoperative gangrene, postoperative SSI, and abnormal wound healing are at an elevated risk for amputation. ${ }^{64,65}$ For this

Table 2 Preoperative risk factors for poor outcomes

\begin{tabular}{|c|c|}
\hline Surgical site complications & Adverse systemic events \\
\hline Graft infection & Cardiovascular \\
\hline $\begin{array}{l}\text { Female sex, diabetes mellitus, active infection at time of } \\
\text { bypass, and redo bypass. }{ }^{51}\end{array}$ & $\begin{array}{l}\text { Dependent functional status, smoking history, diabetes, heart failure, prior } \\
\text { percutaneous coronary intervention or cardiac surgery, angina } \leq \mathrm{I} \text { month before }\end{array}$ \\
\hline Graft failure & surgery or myocardial infarction $\leq 6$ months, and emergent case status. ${ }^{12}$ \\
\hline Acute: age, preoperative ambulatory status, advanced PAD, & Respiratory \\
\hline long duration of surgery, and intraoperative local trauma. ${ }^{59}$ & Smoking status, recent $\mathrm{MI}, \mathrm{CHF}, \mathrm{COPD}$ requiring oxygen, and low body weight. ${ }^{69,70}$ \\
\hline Chronic: prosthetic graft, hypertension, diabetes, and & Renal failure \\
\hline \multirow[t]{8}{*}{ hyperlipidemia. ${ }^{58}$} & Male sex, $\mathrm{CHF}$, diabetes, and angiotensin-converting enzyme inhibitor or angiotensin \\
\hline & receptor blocker use. ${ }^{71}$ \\
\hline & Cerebrovascular accident \\
\hline & Preoperative ventilation, previous CVA, postoperative $\mathrm{MI}$, and return to operating \\
\hline & room. ${ }^{73}$ \\
\hline & Venous thromboembolism \\
\hline & Dependent functional status, metastatic cancer, surgical site infection, postoperative \\
\hline & CVA, preoperative ventilation, and return to operating room. ${ }^{76}$ \\
\hline
\end{tabular}
Abbreviations: PAD, peripheral arterial disease; Ml, myocardial infarction; CHF, congestive heart failure; COPD, chronic obstructive pulmonary disease; CVA, cerebrovascular accident. 
cohort, management of the underlying conditions is vital to improved outcomes postoperatively.

\section{Adverse systemic events}

Infrainguinal bypass is also associated with certain adverse systemic events including, but not limited to, cardiovascular injury, respiratory failure, and death (Table 1). As for local outcomes, a number of patient characteristics and comorbidities have been shown to predict increased global morbidity and mortality (Table 2).

Of all global morbidity associated with infrainguinal bypass, cardiac complications are the most common, occurring in $6.3 \%$ of patients. ${ }^{66}$ Much of this is tied to the similarity in the pathophysiology of PAD and cardiac events, where patients undergoing lower extremity bypass are prone to the same risk factors for cardiac injury. Such factors include dependent functional status, smoking history, diabetes, heart failure, prior percutaneous coronary intervention or cardiac surgery, angina $\leq 1$ month before surgery or myocardial infarction (MI) $\leq 6$ months, and emergent case status. ${ }^{12}$ The predisposition for cardiac injury often manifests during the physiologic stress caused by surgery, resulting in cardiovascular accident such as MI, arrhythmia, and congestive heart failure (CHF). Prognostication tools such as the Revised Cardiac Risk Index can be used to assess probability for perioperative cardiac events and determine a patient's indication for surgery. ${ }^{67}$ This type of risk stratification allows for better informed consent, closer postoperative monitoring, and better assessment of outcome retrospectively. Antiplatelet and antilipid therapies have not been shown to decrease the risk for perioperative cardiovascular accident. ${ }^{6}$

Postoperative respiratory events, defined as pneumonia and reintubation after initial extubation, are also prevalent in the perioperative window following infrainguinal bypass. Respiratory events are present in $2.5 \%$ of patients and are more likely to occur in patients who smoke, had a recent MI, have symptomatic CHF, and have chronic obstructive pulmonary disease (COPD) requiring oxygen. ${ }^{69}$ Furthermore, respiratory adverse events are also tied to low body weight, indicating inadequate nutrition. ${ }^{69,70}$ Thus, patient diet may signify a possible point of intervention in prevention of postoperative respiratory events. If left uncompensated, respiratory events often progress to death and are a major cause of postoperative mortality.

Infrainguinal bypass patients not on dialysis preoperatively have been shown to be at risk of developing AKI. AKI has been reported at rates of $4 \%$ perioperatively and is especially prevalent in patients predisposed to perioperative prescription of nephrotoxic medications such as antibiotics, systemic hypotension, and renal vessel hypoperfusion as a result of atherosclerosis. ${ }^{71}$ Thus, management of patient volume status and renal perfusion is vital in preventing AKI and subsequent renal failure. Furthermore, development of $\mathrm{AKI}$ is associated with various preoperative demographics and comorbidities including male sex, $\mathrm{CHF}$, diabetes, and angiotensin-converting enzyme inhibitor or angiotensin receptor blocker use. ${ }^{71}$ Patients with postoperative AKI have a $90 \%$ increased risk of developing chronic renal insufficiency requiring life-long dialysis dependence and are also more likely to experience cardiovascular accident and mortality. ${ }^{71,72}$

Cerebrovascular accident (CVA) including stroke and transient ischemic attack may occur perioperatively in $1.5 \%$ of patients. ${ }^{11}$ As for cardiac complications, many of the risk factors for CVA are the same as those that contribute to the development of infrainguinal occlusive disease. Independent predictors for CVA include preoperative ventilation, previous CVA, postoperative $\mathrm{MI}$, and reoperation. ${ }^{73} \mathrm{CVA}$ following infrainguinal bypass is generally embolic in etiology, and cardioprotective medications such as antiplatelet therapy and statins have been shown to reduce occurrence of CVA in this cohort. ${ }^{74,75}$ Appropriate medical prevention is critical because CVA results in markedly increased disability and mortality in bypass patients. ${ }^{73}$

Venous thromboembolism (VTE) occurs in $1 \%$ of infrainguinal bypass patients within the first 30 days postoperatively, with DVT shown to present at higher rates than pulmonary embolism (PE). ${ }^{76}$ Postoperative venous duplex scanning is only recommended in symptomatic patients. ${ }^{77}$ However, perioperative anticoagulation prophylaxis is normally offered in bypass patients and especially for those with increased predisposition for postoperative VTE. Risk factors include dependent functional status, metastatic cancer, SSI, postoperative CVA, preoperative ventilation, and return to operating room. ${ }^{76}$

The total rate of 30-day perioperative mortality following infrainguinal bypass is $2.9 \%$, and the majority of deaths result from major organ system failure caused by sepsis (33\%), cardiac complications (44\%), and pulmonary complications (38\%). ${ }^{12}$ Furthermore, perioperative mortality is exceedingly high in patients who experience postoperative cardiac arrest requiring cardiopulmonary resuscitation $(\mathrm{CPR})$, with rates at $73 \% .{ }^{78}$ These relatively high mortality rates in the perioperative setting, combined with the frequency of the aforementioned comorbidities, has increased the favorability of less invasive endovascular procedures over bypass in high-risk patients. Decreased perioperative mortality, adjusted for comorbidities, 
of endovascular procedures compared to bypass supports this movement. ${ }^{79}$ However, there are still concerns about durability.

\section{Conclusion}

Open reconstruction remains an important tool in the treatment of infrainguinal occlusive disease. However, open repair can be associated with local and systemic complications, and the identification of patient- and disease-specific risk factors is critical in selecting appropriate methods of surgical management. High-risk patients may warrant an increased level of postoperative monitoring in the intensive care unit (ICU) as preoperative coronary and carotid interventions have not been shown to be of benefit. The use of less invasive percutaneous methods is an important consideration in high-risk patients if adequate results can be obtained.

\section{Disclosure}

The authors report no conflicts of interest in this work.

\section{References}

1. Norgren L, Hiatt WR, Dormandy JA, et al. Inter-Society Consensus for the Management of peripheral arterial disease (TASC II). J Vasc Surg. 2007;45(suppl S):S5-S67.

2. Hirsch AT, Hartman L, Town RJ, Virnig BA. National health care costs of peripheral arterial disease in the Medicare population. Vasc Med. 2008;13(3):209-215.

3. Conte MS, Pomposelli FB, Clair DG, et al. Society for Vascular Surgery practice guidelines for atherosclerotic occlusive disease of the lower extremities: management of asymptomatic disease and claudication. $J$ Vasc Surg. 2015;61(suppl 3):2S.e1-41S.e1.

4. Gallagher KA, Meltzer AJ, Ravin RA, et al. Endovascular management as first therapy for chronic total occlusion of the lower extremity arteries: comparison of balloon angioplasty, stenting, and directional atherectomy. J Endovasc Ther. 2011;18(5):624-637.

5. Dua A, Lee CJ. Epidemiology of peripheral arterial disease and critical limb ischemia. Tech Vasc Interv Radiol. 2016;19(2):91-95.

6. Vartanian SM, Conte MS. Surgical intervention for peripheral arterial disease. Circ Res. 2015;116(9):1614-1628.

7. DeRubertis BG, Faries PL, McKinsey JF, et al. Shifting paradigms in the treatment of lower extremity vascular disease: a report of 1000 percutaneous interventions. Ann Surg. 2007;246(3):415-422; discussion 422-4.

8. Siracuse JJ, Giles KA, Pomposelli FB, et al. Results for primary bypass versus primary angioplasty/stent for intermittent claudication due to superficial femoral artery occlusive disease. J Vasc Surg. 2012;55(4):1001-1007.

9. Bradbury AW, Adam DJ, Bell J, et al. Bypass versus Angioplasty in Severe Ischaemia of the Leg (BASIL) trial: a survival prediction model to facilitate clinical decision making. J Vasc Surg. 2010;51(5 suppl):52S-68S.

10. Conte MS. Critical appraisal of surgical revascularization for critical limb ischemia. J Vasc Surg. 2013;57(suppl 2):8S-13S.

11. Conte MS, Bandyk DF, Clowes AW, Moneta GL, Namini H, Seely L. Risk factors, medical therapies and perioperative events in limb salvage surgery: observations from the PREVENT III multicenter trial. $J$ Vasc Surg. 2005;42(3):456-464; discussion 464-5.

12. Meltzer AJ, Graham A, Connolly PH, et al. The Comprehensive Risk Assessment for Bypass (CRAB) facilitates efficient perioperative risk assessment for patients with critical limb ischemia. J Vasc Surg. 2013;57(5):1186-1195.
13. Ouriel K, Zarins CK. Doppler ankle pressure: an evaluation of three methods of expression. Arch Surg. 1982;117(10):1297-1300.

14. Bloor K. Natural history of arteriosclerosis of the lower extremities: Hunterian lecture delivered at the Royal College of Surgeons of England on 22nd April 1960. Ann R Coll Surg Engl. 1961;28(1):36-52.

15. Aquino R, Johnnides C, Makaroun M, et al. Natural history of claudication: long-term serial follow-up study of 1244 claudicants. JVasc Surg. 2001;34(6):962-970.

16. Muluk SC, Muluk VS, Kelley ME, et al. Outcome events in patients with claudication: a 15 -year study in 2777 patients. J Vasc Surg. 2001;33(2):251-258.

17. Fowkes FGR, Rudan D, Rudan I, et al. Comparison of global estimates of prevalence and risk factors for peripheral artery disease in 2000 and 2010: a systematic review and analysis. Lancet. 2013;382(9901):1329-1340.

18. Varu VN, Hogg ME, Kibbe MR. Critical limb ischemia. J Vasc Surg. 2010;51(1):230-241.

19. Brass EP, Anthony R, Dormandy J, et al. Parenteral therapy with lipoecraprost, a lipid-based formulation of a PGE1 analog, does not alter six-month outcomes in patients with critical leg ischemia. J Vasc Surg. 2006;43(4):752-759.

20. Bradbury AW, Adam DJ, Bell J, et al. Multicentre randomised controlled trial of the clinical and cost-effectiveness of a bypass-surgery-first versus a balloon-angioplasty-first revascularisation strategy for severe limb ischaemia due to infrainguinal disease. The Bypass versus Angioplasty in Severe Ischaemia of the Leg (BASIL) trial. Health Technol Assess. 2010;14(14):1-210,iii-iv.

21. Adam DJ, Beard JD, Cleveland T, et al. Bypass versus angioplasty in severe ischaemia of the leg (BASIL): multicentre, randomised controlled trial. Lancet. 2005;366(9501):1925-1934.

22. Forbes JF, Adam DJ, Bell J, et al. Bypass versus Angioplasty in Severe Ischaemia of the Leg (BASIL) trial: health-related quality of life outcomes, resource utilization, and cost-effectiveness analysis. JVasc Surg. 2010;51(5 suppl):43S-51S.

23. Menard MT, Farber A, Assmann SF, et al. Design and rationale of the best endovascular versus best surgical therapy for patients with critical limb ischemia (BEST-CLI) trial. JAm Heart Assoc. 2016;5(7):e003219.

24. Siracuse JJ, Van Orden K, Kalish JA, et al. Endovascular treatment of the common femoral artery in the Vascular Quality Initiative. $J$ Vasc Surg. 2017;65(4):1039-1046.

25. Andrews RT, Venbrux AC, Magee CA, Bova DA. Placement of a flexible endovascular stent across the femoral joint: an in vivo study in the swine model. J Vasc Interv Radiol. 1999;10(9):1219-1228.

26. Park SI, Won JH, Kim BM, Kim JK, Lee DY. The arterial folding point during flexion of the hip joint. Cardiovasc Intervent Radiol. 2005;28(2):173-177.

27. Bonvini RF, Rastan A, Sixt S, et al. Endovascular treatment of common femoral artery disease: medium-term outcomes of 360 consecutive procedures. J Am Coll Cardiol. 2011;58(8):792-798.

28. Bonvini RF, Rastan A, Sixt S, et al. Angioplasty and provisional stent treatment of common femoral artery lesions. $J$ Vasc Interv Radiol. 2013;24(2):175-183.

29. Siracuse JJ, Gill HL, Schneider DB, et al. Assessing the perioperative safety of common femoral endarterectomy in the endovascular era. Vasc Endovascular Surg. 2014;48(1):27-33.

30. Kang JL, Patel VI, Conrad MF, Lamuraglia GM, Chung TK, Cambria RP. Common femoral artery occlusive disease: contemporary results following surgical endarterectomy. J Vasc Surg. 2008;48(4):872-877.

31. Pereira CE, Albers M, Romiti M, Brochado-Neto FC, Pereira CAB. Meta-analysis of femoropopliteal bypass grafts for lower extremity arterial insufficiency. J Vasc Surg. 2006;44(3):510-517.

32. Taylor LM, Edwards JM, Brant B, Phinney ES, Porter JM. Autogenous reversed vein bypass for lower extremity ischemia in patients with absent or inadequate greater saphenous vein. Am J Surg. 1987;153(5):505-510.

33. Schanzer A, Hevelone N, Owens CD, et al. Technical factors affecting autogenous vein graft failure: observations from a large multicenter trial. J Vasc Surg. 2007;46(6):1180-1190. 
34. Faries PL, Arora S, Pomposelli FB, et al. The use of arm vein in lowerextremity revascularization: results of 520 procedures performed in eight years. JVasc Surg. 2000;31(1 pt 1):50-59.

35. Klinkert P, Schepers A, Burger DHC, van Bockel JH, Breslau PJ. Vein versus polytetrafluoroethylene in above-knee femoropopliteal bypass grafting: five-year results of a randomized controlled trial. J Vasc Surg. 2003;37(1):149-155.

36. Johnson WC, Lee KK. A comparative evaluation of polytetrafluoroethylene, umbilical vein, and saphenous vein bypass grafts for femoral-popliteal above-knee revascularization: a prospective randomized Department of Veterans Affairs cooperative study. J Vasc Surg. 2000;32(2):268-277.

37. van de Weijer MAJ, Kruse RR, Schamp K, Zeebregts CJ, Reijnen MMPJ. Morbidity of femoropopliteal bypass surgery. Semin Vasc Surg 2015;28(2):112-121.

38. Conte MS, Bandyk DF, Clowes AW, et al. Results of PREVENT III: a multicenter, randomized trial of edifoligide for the prevention of vein graft failure in lower extremity bypass surgery. J Vasc Surg. 2006;43(4):742.e1-751.e1.

39. Hirsch AT, Haskal ZJ, Hertzer NR, et al. ACC/AHA 2005 practice guidelines for the management of patients with peripheral arterial disease (lower extremity, renal, mesenteric, and abdominal aortic). Circulation. 2006;113(11):e463-e654.

40. Albers M, Romiti M, Brochado-Neto FC, Pereira CAB. Meta-analysis of alternate autologous vein bypass grafts to infrapopliteal arteries. $J$ Vasc Surg. 2005;42(3):449-455.

41. Kashyap VS, Ahn SS, Quinones-Baldrich WJ, et al. Infrapopliteal-lower extremity revascularization with prosthetic conduit: a 20-year experience. Vasc Endovascular Surg. 2002;36(4):255-262.

42. Nguyen LL, Hevelone N, Rogers SO, et al. Disparity in outcomes of surgical revascularization for limb salvage. Circulation. 2009;119(1):123-130.

43. Forsythe RO, Jones KG, Hinchliffe RJ. Distal bypasses in patients with diabetes and infrapopliteal disease technical considerations to achieve success. Int J Low Extrem Wounds. 2014;13(4):347-362.

44. Shah DM, Darling RC, Chang BB, Fitzgerald KM, Paty PS, Leather RP. Long-term results of in situ saphenous vein bypass. Analysis of 2058 cases. Ann Surg. 1995;222(4):438-446; discussion 446-8.

45. Brochado Neto F, Sandri GA, Kalaf MJ, et al. Arm vein as an alternative autogenous conduit for infragenicular bypass in the treatment of critical limb ischaemia: a 15 year experience. Eur J Vasc Endovasc Surg. 2014;47(6):609-614.

46. Arvela E, Söderström M, Albäck A, Aho P-S, Venermo M, Lepäntalo M. Arm vein conduit vs prosthetic graft in infrainguinal revascularization for critical leg ischemia. J Vasc Surg. 2010;52(3):616-623.

47. Veith FJ, Gupta SK, Ascer E, et al. Six-year prospective multicenter randomized comparison of autologous saphenous vein and expanded polytetrafluoroethylene grafts in infrainguinal arterial reconstructions. J Vasc Surg. 1986;3(1):104-114.

48. Lindholt JS, Gottschalksen B, Johannesen N, et al. The Scandinavian

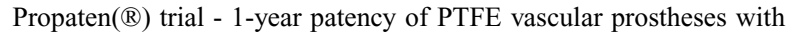
heparin-bonded luminal surfaces compared to ordinary pure PTFE vascular prostheses - a randomised clinical controlled multi-centre trial. Eur J Vasc Endovasc Surg. 2011;41(5):668-673.

49. Heyligers JMM, Lisman T, Verhagen HJM, Weeterings C, de Groot PG, Moll FL. A heparin-bonded vascular graft generates no systemic effect on markers of hemostasis activation or detectable heparin-induced thrombocytopenia-associated antibodies in humans. J Vasc Surg. 2008;47(2):324-329; discussion 329.

50. Patel VI, Hamdan AD, Schermerhorn ML, et al. Lower extremity arterial revascularization in obese patients. J Vasc Surg. 2007;46(4):738-742.

51. Siracuse JJ, Nandivada P, Giles KA, et al. Prosthetic graft infections involving the femoral artery. J Vasc Surg. 2013;57(3):700-705.

52. Siracuse JJ, Huang ZS, Gill HL, et al. Defining risks and predicting adverse events after lower extremity bypass for critical limb ischemia. Vasc Health Risk Manag. 2014;10:367-374.
53. Dosluoglu HH, Loghmanee C, Lall P, Cherr GS, Harris LM, Dryjski ML. Management of early ( $<30$ day) vascular groin infections using vacuum-assisted closure alone without muscle flap coverage in a consecutive patient series. J Vasc Surg. 2010;51(5):1160-1166.

54. Morasch MD, Sam AD, Kibbe MR, Hijjawi J, Dumanian GA. Early results with use of gracilis muscle flap coverage of infected groin wounds after vascular surgery. J Vasc Surg. 2004;39(6):1277-1283.

55. Landry GJ, Carlson JR, Liem TK, Mitchell EL, Edwards JM, Moneta GL. The sartorius muscle flap: an important adjunct for complicated femoral wounds involving vascular grafts. Am J Surg. 2009;197(5):655659; discussion 659

56. Tinder CN, Bandyk DF. Detection of imminent vein graft occlusion: what is the optimal surveillance program? Semin Vasc Surg. 2009;22(4):252-260.

57. Sarkar S, Salacinski HJ, Hamilton G, Seifalian AM. The mechanical properties of infrainguinal vascular bypass grafts: their role in influencing patency. Eur J Vasc Endovasc Surg. 2006;31(6):627-636.

58. Dawson I, van Bockel JH. Reintervention and mortality after infrainguinal reconstructive surgery for leg ischaemia. $\mathrm{Br} J \mathrm{Surg}$. 1999;86(1):38-44.

59. Tan T-W, Farber A, Hamburg NM, et al. Blood transfusion for lower extremity bypass is associated with increased wound infection and graft thrombosis. JAm Coll Surg. 2013;216(5):1005.e2-1014.e2; quiz 1031-3.

60. Calligaro KD, Syrek JR, Dougherty MJ, et al. Selective use of duplex ultrasound to replace preoperative arteriography for failing arterial vein grafts. J Vasc Surg. 1998;27(1):89-95.

61. McBride OMB, Mofidi R, Griffiths GD, Dawson AR, Chalmers RTA, Stonebridge PA. Development of a decision tree to streamline infrainguinal vein graft surveillance. Ann Vasc Surg. 2016;36:182-189.

62. Berceli SA, Hevelone ND, Lipsitz SR, et al. Surgical and endovascular revision of infrainguinal vein bypass grafts: analysis of midterm outcomes from the PREVENT III trial. JVasc Surg. 2007;46(6):1173-1179.

63. Soden PA, Zettervall SL, Shean KE, et al. Effect of adjunct femoral endarterectomy in lower extremity bypass on perioperative and 1-year outcomes. J Vasc Surg. 2017;65(3):711.e1-719.e1.

64. Smith AD, Hawkins AT, Schaumeier MJ, de Vos MS, Conte MS, Nguyen LL. Predictors of major amputation despite patent bypass grafts. J Vasc Surg. 2016;63(5):1279-1288.

65. Kaminski MR, Raspovic A, McMahon LP, et al. Risk factors for foot ulceration and lower extremity amputation in adults with end-stage renal disease on dialysis: a systematic review and meta-analysis. Nephrol Dial Transplant. 2015;30(10):1747-1766.

66. Bertges DJ, Goodney PP, Zhao Y, et al. The Vascular Study Group of New England Cardiac Risk Index (VSG-CRI) predicts cardiac complications more accurately than the Revised Cardiac Risk Index in vascular surgery patients. J Vasc Surg. 2010;52(3):674.e3-683.e3.

67. Goldman L, Caldera DL, Nussbaum SR, et al. Multifactorial index of cardiac risk in noncardiac surgical procedures. $N$ Engl J Med. 1977;297(16):845-850.

68. De Martino RR, Beck AW, Hoel AW, et al. Preoperative antiplatelet and statin treatment was not associated with reduced myocardial infarction after high-risk vascular operations in the Vascular Quality Initiative. $J$ Vasc Surg. 2016;63(1):182.e2-189.e2.

69. Genovese EA, Fish L, Chaer RA, Makaroun MS, Baril DT. Risk stratification for the development of respiratory adverse events following vascular surgery using the Society of Vascular Surgery's Vascular Quality Initiative. J Vasc Surg. 2017;65(2):459-470.

70. Birkmeyer NJ, Charlesworth DC, Hernandez F, et al. Obesity and risk of adverse outcomes associated with coronary artery bypass surgery. Northern New England Cardiovascular Disease Study Group. Circulation. 1998;97(17):1689-1694.

71. Flores E, Lewinger JP, Rowe VL, et al. Increased risk of mortality after lower extremity bypass in individuals with acute kidney injury in the Vascular Quality Initiative. J Vasc Surg. 2017;65(4):1055-1061.

72. Bucaloiu ID, Kirchner HL, Norfolk ER, Hartle JE, Perkins RM. Increased risk of death and de novo chronic kidney disease following reversible acute kidney injury. Kidney Int. 2012;81(5):477-485. 
73. Axelrod DA, Stanley JC, Upchurch GR Jr, et al. Risk for stroke after elective noncarotid vascular surgery. J Vasc Surg. 2004;39(1):67-72.

74. Mangano DT; Multicenter Study of Perioperative Ischemia Research Group. Aspirin and mortality from coronary bypass surgery. $N$ Engl $J$ Med. 2002;347(17):1309-1317.

75. Byington RP, Davis BR, Plehn JF, et al. Reduction of stroke events with pravastatin: the Prospective Pravastatin Pooling (PPP) Project. Circulation. 2001;103(3):387-392.

76. Ramanan B, Gupta PK, Sundaram A, et al. In-hospital and postdischarge venous thromboembolism after vascular surgery. J Vasc Surg. 2013;57(6):1589-1596.

77. Passman MA, Farber MA, Marston WA, et al. Prospective screening for postoperative deep venous thrombosis in patients undergoing infrainguinal revascularization. J Vasc Surg. 2000;32(4):669-675.
78. Siracuse JJ, Meltzer EC, Gill HL, et al. Outcomes and risk factors of cardiac arrest after vascular surgery procedures. J Vasc Surg. 2015;61(1):197-202.

79. Siracuse JJ, Menard MT, Eslami MH, et al. Comparison of open and endovascular treatment of patients with critical limb ischemia in the Vascular Quality Initiative. J Vasc Surg. 2016;63(4):958.e1-965.e1.

80. Geraghty AJ, Welch K. Antithrombotic agents for preventing thrombosis after infrainguinal arterial bypass surgery. Cochrane Database Syst Rev. 2011;6:CD000536.

81. Alabi O, Roos M, Landry G, Moneta G. Quality-of-life assessment as an outcomes measure in critical limb ischemia. JVasc Surg. 2017;65(2):571-578.

82. Rollins KE, Coughlin PA. Functional outcomes following revascularisation for critical limb ischaemia. Eur J Vasc Endovasc Surg. 2012;43(4):420-425.

\section{Publish your work in this journal}

Vascular Health and Risk Management is an international, peerreviewed journal of therapeutics and risk management, focusing on concise rapid reporting of clinical studies on the processes involved in the maintenance of vascular health; the monitoring, prevention and treatment of vascular disease and its sequelae; and the involvement of metabolic disorders, particularly diabetes. This journal is indexed on PubMed Central and MedLine. The manuscript management system is completely online and includes a very quick and fair peer-review system, which is all easy to use. Visit http://www.dovepress.com/ testimonials.php to read real quotes from published authors. 